\begin{tabular}{|c|c|}
\hline & $\begin{array}{l}\text { International Journal of Trend in Scientific } \\
\text { Research and Development (IJTSRD) }\end{array}$ \\
\hline 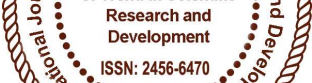 & International Open Access Journal \\
\hline 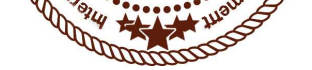 & ISSN No: 2456 - 6470 | www.ijtsrd.com | Volume - 2 | Issue - 2 \\
\hline
\end{tabular}

\title{
Case Study on :"Marketing strategies of Henry Ford of heart surgery - Narayana Health Care also known as Narayana Hrudayalaya, Leading India in World for Health care"
}

\author{
Dr. Manish Gupta \\ ASM's Institute Of Business Management and Research, \\ Chinchward, Pune, India
}

\section{ABSTRACT}

"Bengal Famine was not due to lack of food, it is the lack of paying capacity to buy food"- Dr. Amartya Sen

In 2001, Shetty founded Narayana Hrudayalaya (NH), a multi-specialty hospital in Bommasandra on the outskirts of Bangalore. He believes that the cost of healthcare can be reduced by 50 percent in the next 5 10 years if hospitals adopt the idea of economies of scale. Apart from cardiac surgery, NH also has cardiology, neurosurgery, paediatric surgery, haematology and transplant services, and nephrology among various others. The heart hospital is the largest in the world with 1000 beds performing over 30 major heart surgeries a day. The land, on which the health city was built, was previously a marshland which was reclaimed for this purpose. The Health City intends to cater to about 15,000 outpatients every day. In August 2012, Shetty announced an agreement with TriMedx, a subsidiary of Ascension Health, to create a joint venture for a chain of hospitals in India. In the past Narayana Hrudayalaya has collaborated with Ascension Health to set up a health care city in the Cayman Islands, planned to eventually have 2,000 beds.

The case highlights how successful entrepreneurship can be done using technologies, the case is unique as it on social entrepreneurship, today is the world of Start-ups who use technologies, and case highlights how innovation ideas come from technologies use.
Key words: Healthcare, Technology, low cost

\section{Background}

Devi Prasad Shetty (born 8 May 1953) is an Indian cardiac surgeon. Shetty was born at village Dakshina Kannada district, Karnataka, India. The eighth of nine children, he decided to become a heart surgeon when he was in fifth grade at school after hearing about Dr. Christiaan Barnard, a South African surgeon who had just performed the world's first heart transplant. After completing his graduate degree in Medicine and postgraduate work in General Surgery from Kasturba Medical College, Mangalore, he trained in cardiac surgery at Guy's Hospital in the United Kingdom.

He returned to India in 1989 and initially worked at B.M. Birla Hospital in Kolkata. He successfully performed the first neonatal heart surgery in the country in 1992, on a 9-day-old baby named "Ronnie". In Kolkata he operated on Mother Teresa after she had a heart attack and subsequently served as her personal physician. After some time, he moved to Bangalore and started the Manipal Heart Foundation at Manipal Hospitals, Bangalore. Financial contribution for the construction of the hospital was provided by Shetty's father-in-law Shetty also founded Rabindranath Tagore International Institute of Cardiac Sciences (RTIICS) in Kolkata and signed a memorandum of understanding with the Karnataka Government to build 5,000-bed specialty hospital near Bangalore International Airport. His company signed 
a MOU with the Government of Gujarat, to set up a 5,000 bed hospital at Ahmedabad. He was elected as the chief patron of Indian Association of Clinical Cardiologists during the annual scientific session IACCCON 2013 at Bangalore.

He was a part of the seven-member panel of Board of Governors which replaced the MCI and served for a period of one year before it was further reconstituted. He is chairman and Founder of Narayana Health, a chain of 21 medical centers in India. He has performed over 15,000 heart operations. In 2004 he was awarded the Padma Shri, the fourth highest civilian award followed by the Padma Bhushan in 2012, the third highest civilian award by the Government of India for his contribution to the field of affordable healthcare. He has been awarded Porters award, BCG award, ET entrepreneur award twice 2013 \& 2014, Nikkei Asia prize, Forbes philanthropy awards.

Trusted Brand Decorated with Awards and Recognition

Awards \& Recognitions for the Chairman Dr. Devi Shetty

\begin{tabular}{|l|l|}
\hline Dr. Devi Shetty & $\begin{array}{l}\text { 19th Nikkei Asia Prize } \\
\text { Economic \& Business } \\
\text { Innovation }\end{array}$ \\
\hline 2013 & $\begin{array}{l}\text { Entrepreneur of the year at ET } \\
\text { Awards }\end{array}$ \\
\hline 2012 & Indian of the year by CNN-IBN \\
\hline 2012 & $\begin{array}{l}\text { The Economic Times } \\
\text { Entrepreneur of the Year }\end{array}$ \\
\hline 2012 & Padma Bhushan \\
\hline 2010 & Indian of the year by NDTV \\
\hline 2005 & Social Entrepreneurship Award \\
\hline 2004 & Citizen Extraordinaire, Rotary \\
\hline 2003 & Padma Shri \\
\hline 2003 & $\begin{array}{l}\text { Ernst \& Young -Entrepreneur of } \\
\text { the Year }\end{array}$ \\
\hline 2003 & $\begin{array}{l}\text { Sir M. Visvesvaraya Memorial } \\
\text { Award }\end{array}$ \\
\hline 2002 & Rajyotsava Award \\
\hline
\end{tabular}

\section{Achievements}

Shetty aims for his hospitals to use economies of scale, to allow them to complete heart surgeries at a lower cost than in the United States. In 2009 the Wall Street Journal newspaper described him as "the Henry
Ford of heart surgery" who follows economics of doing surgeries in mass of special kind with same set of doctors having standardized procedure, kaizen improvements in their processes. Six additional hospitals were subsequently planned on the Narayana Hrudayalaya model at several cities in India, with plans to expand to 30,000 beds with hospitals in India, Africa and other countries in Asia. Shetty aims to trim costs with such measures as buying cheaper scrubs and using cross ventilation instead of air conditioning. That has cut the price of coronary bypass surgery (from Rs. 4lacs-3lacs) to 95,000 rupees $(\$ 1,583)$, half of what it was 20 years ago. In 2013 he aimed to get the price down to $\$ 800$ within a decade. The same procedure costs $\$ 206,385$ at Ohio's Cleveland Clinic. He has also eliminated many pre-ops testing and innovated in patient care such as "drafting and training patients' family members to administer aftersurgical care". Surgeons in his hospitals perform 30 to 35 surgeries a day compared to one or two in a US hospital. His hospitals also provide substantial free care especially for poor children. He performs free surgery for the poor.

The entrepreneurship is of social type, not a free charity, which is a viable self-dependent business model, the wealthier get the benefit of subsidized rate, but the difference between actual and selling cost generates revenue for free surgeries at $\mathrm{NH}$ for poor i.e. $5 \%$ of its patients get free surgeries , $27 \%$ subsidized rates At NH Shetty and his family have a 75 percent stake in Narayana Hrudayalaya which he plans to preserve. Shetty has also pioneered low-cost diagnostic services.

\section{3 heart surgeries a day \\ - Heart surgery for Rs.65,000 \\ - Coronary angiogram for Rs.4500 \\ - World's largest pediatric cardiac surgery unit. \\ ○ In an Industry where disposables comprise $45 \%$ of the cost, it is the number game. \\ - Large number reduces the cost and improves result. \\ ○ Two Health City projects of 5000 bed each. \\ - Break up complex task into many islands of excellence \\ - Replacing the moving parts of a medical equipment to PCB's can reduce cost to any level}

\section{Technological Use}

Technology gives the rich what they already have but it gives the poor what they can never dream of having 
Use SMS, AI, Robotics and mix of technologies in healthcare i.e like NH hospital S.M.S. each senior staff of a hospital each day about expense at that hospital on operations, sets weekly, monthly targets for cost saving in their areas, so that next day surgeries the doctors team can look into save some cost and improving EBIT.

Telemedicine for access to remote areas in north east like Agartala, principles of Telemedices:

- Less than $1 \%$ of the sick requires an operation

- If you do not need to operate, you don't need to touch

- If you don't need to touch, you don't need to be there

○ 6 hours following the heart attack is the golden period.

- A joint venture of Indian space research organization, Asia heart foundation Narayana Hrudayalaya and various state governments

- 22 telemedicine centers

- Over 16,000 patients treated free

- Free telemedicine software from SN informatics

- Free MRI Scan

- Trans Telephonic ECG Network

- Digital X-ray - a Joint Venture with Texas Instrument

- Mobile Diagnostic Lab

- Use of global supply chain logistics for generic medicines and medical equipment.

- Close link with pharma \& medical equipment majors for clinical trials, offering at reduced cost, guaranteed volume.

Indian Healthcare Industry at a Glance Sector Outlook:

- Indian healthcare market is expected to reach US $\$ 280$ bn by 2020 , a CAGR of $23 \%$ between FY15-20E

○ Hospital segment constitutes $\sim 71 \%$ of the market

- Medical tourism to contribute 15-20\% to hospital revenue by FY20 from 5-10\% currently

Inadequate Infrastructure:

○ Out-of-pocket expenditure on healthcare is $\sim 61 \%$ the highest in the world

○ 7 beds per 10,000population vs global average of 26 beds

- $3 \%$ specialist physicians cater to rural areas which comprises $>70 \%$ of population
- India's per capita income is expected to register a CAGR of 11\%between FY16-21E

- Deaths due to NCDs are expected to be $74 \%$ of total deaths in 2030 compared with 60\% in 2012

○ $<20 \%$ population has health insurance, INR 20/day premiums for coverage of INR $0.5 \mathrm{mn}$ are available

Key Growth Drivers

○ National Health Policy 2017 has set Ambitious Targets: Universal healthcare coverage -Increase health expenditure as a percentage of GDP from the existing $1.15 \%$ to $2.50 \%$ by 2025

○ Demand Outstrips Supply: 1.7mn beds required to meet India's healthcare needs by 2025

- More Lifestyle Centric Diseases and Rising Urbanisation:35\% cardiovascular-ailment related share in incidents of death by 2030 compared with $31 \%$ in 2015

- Share of Older Population to Rise: $27 \%$ of total population will fall in 45-60+ age group by 2021 from $22 \%$ in 2011

- India's Recognition at World Stage in Healthcare Solutions:Tertiary care facilities at lower cost with ease in visa procurement to drive patients from South East Asia and Middle East

Present in 2017 Narayana a Leading Pan-India Multispeciality Healthcare Group

NH's footprint in India: Mumbai, Kolkata, Ahmedabad, Raipur, Jamshedpur, Durgapur, Guwahati, Kakriyal, Jammu, Palanpur, Mahuva, Bellary, Shimoga, Bengaluru, Mysore, Delhi NCR, Jaipur.

\section{Reach region wise:}

Northern Region, 2 hospitals and 1 upcoming facility in NCR, Operational beds: 335

Eastern Region: 9 hospitals

Operational beds: 1,934

Kolkata has 6 hospitals (3 are acquired)

Karnataka Region: 7Hospitals, Operational beds: 2,161

Western Region: Hospitals, Operational beds: 1,011

Growth Prospects: 
International Journal of Trend in Scientific Research and Development (IJTSRD) ISSN: 2456-6470

Existing Hospital

\begin{tabular}{|l|l|l|}
\hline $\begin{array}{l}\text { Planned } \\
\text { Facility51 }\end{array}$ & Healthcare Facilities & $\begin{array}{l}\text { Operational } \\
\text { beds }\end{array}$ \\
\hline 20 & $\begin{array}{l}\text { Owned / Operated } \\
\text { Hospitals(1) }\end{array}$ & 4,721 Beds \\
\hline 4 & $\begin{array}{l}\text { Managed } \\
\text { Hospitals(2) }\end{array}$ & 720 Beds \\
\hline 7 & Heart Centres & 376 Beds \\
\hline 19 & $\begin{array}{l}\text { Primary Healthcare } \\
\text { Facilities(3) }\end{array}$ & 10 Beds \\
\hline 1 & $\begin{array}{l}\text { Hospital in Cayman } \\
\text { Islands }\end{array}$ & 105 Beds \\
\hline
\end{tabular}

7181 capacity beds

5932 operational beds

2.7million rupees average effective cost per operational bed.

$30+$ Specialty

$343+$ Procedures/Day

14330 Full time employees \& Associates including 3011 doctors

Today in 2017 as per NHL, they have 51 health care facilities, 20 owned hospitals with 4721 beds, 4 managed hospitals with 720 beds, 7 heart care facilities with 376 beds, 19 primary health care facilities, and 1 hospital in Caymen Island with 105 beds. Total 7181 bed there in NHL, they are performing 343/ day heart surgeries and procedures, 14330 employees with 3011 doctors are working in NHL, NHL had in 2017 turnover of @ Rs.188 Crore with profit before tax@Rs15 Crore.

Evolving Case Mix with Leadership in Cardiac \& Renal Sciences and Growing Share of Other Specialities:

De-risking business model by expanding the service spectrum (1):

The department of cardiology $\square$ carried out the first TranscatheterAortic Valve Implantation (TAVI) in India

○ 35,000 angiogram, $\sim 12,000$ angioplasty, $\sim 2.25$ Lacsdialysis sessions conducted in FY17

- Performed 35 heart transplants and 2,976 renal transplants till date

- NH operates one of the largest $\square$ Bone Marrow Transplants unit in the country with over 160 BMTs done in FY17

- NH's unit at Howrah is recognized as the Centre for Excellence in the field of Oncology
- Da Vinci Robotic Surgical program has so far performed over 150 surgeries in last 10 months of commissioning

- NH has started advanced gastroenterology programs at facilities in Mysore and Jaipur

- Performed 72 liver transplants till date

- Major emphasis on diseases such as Parkinson's, DBS, Epilepsy treatment

- NH delivers specialized care in complex trauma, polytraumaand related sub specialities

Six core specialities contribute $89 \%$ to group's revenues: Cardiac and Renal Sciences, Oncology, Gastro Intestinal Sciences, Neurosciences

Orthopaedics

NHL recognized that "Poor people in isolation are weak but together they are very strong" started Yeshasvini micro health insurance with premium Rs. 5/ Month, with Govt. of Karnataka as partner, Govt. which contributes Rs.7.5/ Monthwith aim that:

Unless you address the problem of paying capacity building hospitals is not going to solve the health problem, High interest rate, $35 \%$ occupancy in normal hospitals giving heart care in general, rural indebtedness is mainly because of health problems.

Yeshasvini micro health insurance is a joint venture of the Karnataka State Co-operation Dept. and Narayana Hrudayalaya/ Asia Heart Foundation. It has 1.7 Million farmer members in the first year, 2.5 Million farmer members in the second year, 85,000 farmers had free medical treatment, 22,000 farmers had free surgeries, and 1400 farmers had heart surgeries.

Arogya raksha yojna:

A comprehensive Health scheme for Anekal Taluk, Bangalore

- Joint venture of Narayana Hrudayalaya, Biocon and ICICI

- Free OPD consultation

- Diagnostics at discounted rates

- 3 days inpatient treatment

- Cashless surgical facility

- Generic drugs at $30 \%$ of the market rate.

- Provide a vehicle for the common man to contribute a tiny amount of money every month to cover his healthcare. 
Training people for health care is the key to give people quality care via: IGNOU Courses at Narayana Health:

$>$ Diploma in Community Cardiology

$>$ Diploma in Community Nephrology

$>$ Diploma in Community Neurology

$>$ Diploma in Community Endocrinology

Key Highlights 2017:

> Narayana Institute of Cardiac Sciences, Bengaluru, became the first hospital in the country to introduce a new smart-generation catheter device that will correct electrical signals causing disturbance in the heart rhythm

> Da Vinci Robotic Surgical System, installed at MazumdarShaw Medical Centre, Bengaluru, crossed the milestone of performing more than 150 surgeries within 10 months of its commissioning

$>$ Narayana Multispeciality Hospital, Raipur, performed the first Leadless Pacemaker Implant across Central India
Financial Data 2017:

$>$ The facility at Cayman Islands showcased exemplary performance achieving an EBITDA margin of $13.3 \%$ in Q4 FY17 translating to $7.6 \%$ EBITDA margin for the year. The unit achieved this feat within 3 years of its operations

$>\mathrm{NH}$ entered into an agreement for healthcare services with $\sim 300$ capacity bedded Dharamshila Hospital \& Research Centre to mark its maiden foray in NCR

$>$ Operating revenue of INR 4,835 $\mathrm{mn}$ in Q4 FY17, an increase of $13.1 \%$ YoYtranslating into INR $18,782 \mathrm{mn}$ in FY17, an increase of $16.4 \% \mathrm{YoY}$

Q4 FY17 YoY growth in EBITDA by $23.4 \%$ to INR $659 \mathrm{mn}$ and FY17 YoY growth in EBITDA by $30.2 \%$ to INR $2,463 \mathrm{mn}$, reflecting an EBITDA margin of $13.6 \%$ in Q4 FY17 and $13.1 \%$ in FY17 respectively

$>$ FY17 PAT after minority interest and share in loss of associates at INR $831 \mathrm{mn}$ reflectingYoY growth of $291.3 \%$

Net debt of INR 1,826 mn as on 31stMarch, 2017, reflecting net debt to equity ratio of 0.19

Goodwill earning Rs 541 lacs in 2017 compared to 2016 Rs.541lacs.

\section{Consolidated Financial Performance}

As on March 31st, 2017, the consolidated net debt was Rs1,826 mn representing a net debt to equity ratio 0.19

\begin{tabular}{|l|l|l|l|l|}
\hline Profit and Loss Statement(1) Particulars & $\mathbf{Q} 4$ FY16 & Q4 FY17 & FY16 & FY17 \\
\hline Total Operating Revenue & $\mathbf{4 , 2 7 6}$ & $\mathbf{4 , 8 3 5}$ & $\mathbf{1 6 , 1 3 8}$ & $\mathbf{1 8 , 7 8 2}$ \\
\hline $\begin{array}{l}\text { Purchase of medical consumables, drugs and surgical } \\
\text { equipment-Net of change in Inventory }\end{array}$ & 1,025 & 1,084 & 3,871 & 4,359 \\
\hline Employee (Excluding Doctors) Expenses & 780 & 839 & 3,025 & 3,395 \\
\hline Doctors Expenses & 934 & 1,102 & 3,522 & 4,213 \\
\hline Other Admin Expenses & 1,044 & 1,209 & 3,974 & 4,526 \\
\hline Total Expenses & $\mathbf{3 , 7 8 4}$ & $\mathbf{4 , 2 3 4}$ & $\mathbf{1 4 , 3 9 3}$ & $\mathbf{1 6 , 4 9 3}$ \\
\hline Other Income & 42 & 57 & 147 & 175 \\
\hline EBITDA & $\mathbf{5 3 4}$ & $\mathbf{6 5 9}$ & $\mathbf{1 , 8 9 3}$ & $\mathbf{2 , 4 6 3}$ \\
\hline Depreciation and Amortization & 212 & 212 & 761 & 799 \\
\hline Finance Costs & 64 & 56 & 294 & 218 \\
\hline Profit Before Tax \& Exceptional Items & $\mathbf{2 5 7}$ & $\mathbf{3 9 1}$ & $\mathbf{8 3 7}$ & $\mathbf{1 , 4 4 6}$ \\
\hline Exceptional Items & 96 & 0 & 110 & 13 \\
\hline Tax Expense & 77 & 150 & 301 & 524 \\
\hline PAT before MI and share of loss of associates & $\mathbf{8 5}$ & $\mathbf{2 4 1}$ & $\mathbf{4 2 6}$ & $\mathbf{9 0 9}$ \\
\hline Share in (loss)of associates and MI & -34 & -18 & -217 & -79 \\
\hline PAT after MI and share in loss of associates & $\mathbf{5 0}$ & $\mathbf{2 2 3}$ & $\mathbf{2 1 2}$ & $\mathbf{8 3 1}$ \\
\hline Total Comprehensive Income, net of tax & 41 & 221 & 204 & 831 \\
\hline
\end{tabular}




\section{Future}

Year 2008, India world's largest mass healthcare provider

- We produce the largest number of doctors, technicians and nurses in the world

- Policy changes

- Pharmaceutical capacity

- Of course by default

\section{Questions:}

Q1. Trace the entrepreneurial qualities and discuss.

Q2. What is USP of Narayana Healthcare?

Q3. What are the marketing and business strategies adopted by $\mathrm{NH}$ that led to so fast growth of $\mathrm{NH}$ in the country and now going all over world?

Q4. What is the business model made by Narayana Health? Which now Govt. are following?

\section{References:}

1. Narayana

Health.//en.wikipedia.org/wiki/Narayan_Health.

2. www.narayanhealth.org/narayana_health_city.

3. www.internationalpatientcare/naryanahealth.com.

4. www.indiahospitaltour.com/narayana_hospital_he althcity_banglore.htm

\section{Case Study Notes:}

\section{Area and Title selection Criteria:}

Health care is major service contributor to GDP of India, players like Narayana Health $(\mathrm{NH})$ is leading in Health care sector for India In globalisation, the title is based on Wall street Journal's reviews on work $\mathrm{NH}$, who call $\mathrm{NH}$ as Henry ford of Heart surgeries.

\section{Protagonist (Lead character) selection Criteria}

The protagonist in this case study is an entrepreneur who is trying to solve health care issues in the country by his techniques and use of management ideas.

\section{Data Source and Story Development for Case Construction (Hook Effect \& Current Scenario)}

Data for the case was collected from internet search on NH and Dr. Devi Shetty, Wikipedia, NH website giving investors financial reports and assessment from investors view point.
Since most data on case is already on net, the need to take interview and permission from lead character has not been done.

The story of success and social entrepreneurship which is giving free treatment to poor is truly inspiring to look into such a business model, which can be self-sustaining and profitable. The marketing strategies and technological techniques used by $\mathrm{NH}$ are unique in its self.

\section{Short term and Long Term Issues}

Short term effect of $\mathrm{NH}$ on Health care in India has had deep impact; the business model is being copied by several Indian state govt. health care schemes so that they can give healthcare services to poor.

Globally $\mathrm{NH}$ is bringing India fame in Health management model which other countries now want to follow. Patients in our SAARC countries are coming to know about India's true strengths.

Long term effect of $\mathrm{NH}$ is that it is making Healthcare affordable year on year, year on year more state govt. in India adopting its model and model becoming global.

5. Teaching Notes - Course of Studies and Topic Relevance

The case highlights use of:

- Operations management techniques in health care services like mass production/ services, economy of scale, global purchasing, Kaizens.

- Business and marketing Strategies used by NH like USP, business model, operation strategies like Blue Ocean.

- Use of technologies in NH like Telemedicine, generic medicine, S.M.S, new technologies of medical science in surgeries, medical devices like low cost MRI.

- Services and goods concepts: How each of the components in same needs analysis to cut cost adds value to customers.

- How poor countries like India can afford healthcare for masses.

- Resource mobilizations can happen by looking internally first. 


\section{Students may refer to following books:-}

- Baporikar.N. (2008). Case Method- Cases in Management, Himalaya Publishing House, Mumbai.

- Kim.W.C\& Mauborgne. R. (2015). Blue ocean strategies, Harvard business Review press, Boston.

- Prahalad.C.K.(2010), The Fortune at that bottom of Pyramid, Dorling Kindershy, New Delhi.

\section{A Brief Analysis of Issues of the Case and Resolutions to issues}

Read the case 2-3 times, highlight the areas important and make gist and notes on key areas.

The analysis can be done by following ways before framing the resolutions:

\section{1) Analysis:}

- PEST Analysis, SWOT, GE matrix, BCG \&Ansr of Matrix, Porter's 5 Force analysis, Value analysis, margins analysis, why-why analysis.

- Bottom of the pyramid model of marketing goods and services

- Rapid expansion and vertical integration strategies use.

- Global marketing strategies used

- Use of goods and services concepts: How each product has blend of both.

- Use of Blue ocean strategy by protagonist.

\section{2) Collect more data from net}

Detailed data can be collected through inter- net and this will help to solve this case study in a better way.

\section{3) Create Innovate ideas:}

Out of box thinking is required to solve such case studies.

\section{Anything unique about the Case Development Process followed?}

The case highlights how successful entrepreneurship can be done using technologies, the case is unique as it on social entrepreneurship, today is the world of Start-ups who use technologies, and case highlights how innovation ideas come from technologies use.

For developing the case lot of data on same was taken from website and financial reports of the company.
Going through the case you feel proud we have such good people and who do such good entrepreneurial work for the society. 